\title{
FREQÜÊNCIAS DOS GRUPOS SANGÜÍNEOS E INCOMPATIBILIDADES ABO E RHD EM PUÉRPERAS E SEUS RECÉM-NASCIDOS
}

\author{
Eduardo Baiochi*, luiz Camano, Nelson Sass, Osmar Ribeiro Colas \\ Trabalho realizado na Universidade Federal de São Paulo / Escola Paulista de Medicina e Hospital Municipal e Maternidade Escola Vila Nova \\ Cachoeirinha "Dr. Mario de Morais Altenfelder Silva"
}

\author{
*Correspondência: \\ Rua Emilio Mallet, 465 \\ apto 134, Tatuapé \\ São Paulo/SP \\ Cep: 03320-000 \\ Tel: (11) 6674-9305 \\ Fax: (11) 6674-3916 \\ baiochi@ultrarapida.com.br
}

\begin{abstract}
RESUMO
OвjEtrvo. Determinar as freqüências fenotípicas e predizer o risco de incompatibilidade e aloimunização materna $\mathrm{RhD}$ na população da Zona Oeste de São Paulo, Brasil.

Métodos. Estudo descritivo no qual avaliamos 2372 puérperas e seus recém-nascidos vivos, no período de um ano, tipificadas para os sistemas $\mathrm{ABO}$ e RhD por meio de teste de aglutinação em tubo.

Resultados. $O$ estudo mostrou os seguintes percentuais: grupo sangüíneo $0,50,67 \% ; A, 32,17 \% ; B, 13,45 \%$; $A B, 3,71 \%$; $\operatorname{RhD}(+), 90,34 \%$ e $\operatorname{RhD}(-), 9,66 \%$. A ocorrência de incompatibilidade materno-fetal foi de $18,4 \%$ para o sistema $A B O$ e de $7 \%$ para o RhD.

Conclusão. O contingente da população Rh negativa com alto risco para aloimunização RhD foi estimado em $82 \%$, denotando a importância da profilaxia da aloimunização RhD.

UNITERMOs: Antígenos de grupos sangüíneos. Sistema de grupo sangüíneo ABO. Sistema de grupo sangüíneo RhHr. Isoimunização RH.
\end{abstract}

\section{INTRODUÇÃO}

Os grupos sangüíneos $A B O$ e RhD desempenham um importante papel em Obstetrícia. Mulheres RhD negativas, ao gerarem conceptos $\mathrm{RhD}$ positivos (herança paterna) podem ser sensibilizadas, produzindo anticorpos anti-D, que, cruzando a barreira placentária, podem hemolizar eritrócitos fetais, causando anemia hemolítica perinatal (DHPN)'. Por outro lado, a compatibilidade entre mãe e feto para o grupo sangüíneo $A B O$ pode favorecer a aloimunização materna ${ }^{2}$, elevando o risco de sensibilização $\mathrm{RhD}$ de $2 \%$ para $16 \%$, nesta eventualidade ${ }^{3}$ O provável mecanismo envolvido nesta relativa proteção seria a rápida destruição das hemácias fetais incompatíveis pelos anticorpos maternos anti-A e/ou anti-B, o que originou a proposta de utilização de plasma contendo elevados títulos de imunoglobulina na prevenção da sensibilização materna pelo antígeno RhD.

Este conhecimento nos permite estratificar a população obstétrica RhD negativa em dois subgrupos: aquele de alto risco para aloimunização, formado por mulheres $A B O$ compatíveis com seus recém-nados, que deveriam ser o alvo prioritário de políticas públicas visando a profilaxia da sensibilização $\mathrm{RhD}$ e, como alvo secundário, aquelas mulheres $A B O$ incompatíveis com seus conceptos, uma vez que apresentam risco oito vezes menor para desenvolvimento de aloanticorpos $\mathrm{RhD}^{3}$.

\section{Métodos}

Objetivamos neste estudo determinar as freqüências fenotípicas dos sistemas de grupos sangüíneos $A B O$ e $R h D$, entre puérperas e nativivos do Hospital e Maternidade Cachoeirinha, na Zona Oeste de
São Paulo, e avaliar a ocorrência de incompatibilidade $A B O$ e RhD entre mãe e recém-nascido nesta população.

O estudo foi descritivo retrospectivo, tendo levantado, a partir dos registros do banco de sangue, a determinação do grupo sangüíneo $A B O$ e RhD de 2372 puérperas e seus recém-nascidos vivos, que tiveram seu parto no Hospital e Maternidade Vila Nova Cachoeirinha, no período de um ano entre I de agosto de 200 | e 3 | de julho de 2002.

Por ocasião do parto, como parte da rotina de atendimento, foram coletados em tubo com o anticoagulante ácido etilenodiaminotetracético (EDTA) cerca de $5 \mathrm{ml}$ de sangue venoso periférico da parturiente e igual volume de sangue fetal do cordão umbilical remanescente na placenta, após a dequitaçãa, para tipificação $\mathrm{ABO} / \mathrm{Rh} \mathrm{D}$. Todos os testes laboratoriais foram realizados no mesmo serviço, dentro de 24 horas após a coleta, pela técnica em tubo. O método de leitura utilizado foi o da hemaglutinação, conforme Manual Técnico da Associação Americana de Bancos de Sangue 4 .

$A$ determinação do grupo sangüíneo $A B O$ foi realizada pelas técnicas direta e reversa, com o emprego de soros monoclonais anti$A$ e anti-B, procedentes da Biotest $A G \circledast$ (Dreieich, Alemanha) e suspensão de hemácias, a $3 \%$, dos grupos sangüíneos $A, B$, procedentes da Biotest S/A Comércio e Indústria ${ }^{\circledR}$ (São Paulo, Brasil). A tipagem RhD foi realizada com soro policlonal anti-D (Biotest S/A, Brasil). Nos casos em que a aglutinação teve intensidade inferior a $2+$ ou não houve aglutinação, prosseguiu-se a investigação realizando o teste para 0 D-fraco com leitura em fase de antiglobulina (fase de Coombs).

A freqüência de cada um dos fenótipos foi determinada e expressa em porcentagem relativa ao total de indivíduos avaliados.

Este estudo teve parecer favorável da Comissão de Ética do Hospital Maternidade Vila Nova Cachoeirinha. 


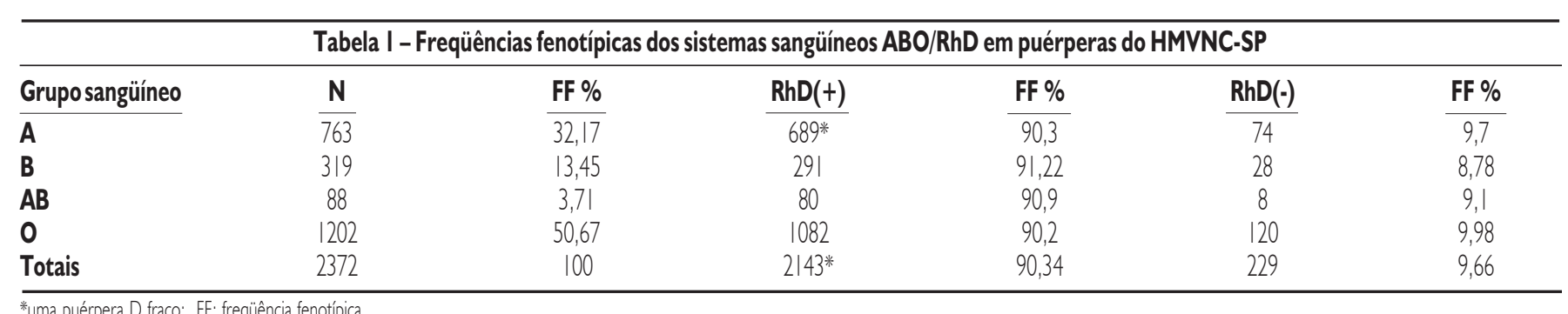

*uma puérpera D fraco; FF: freqüência fenotípica

\begin{tabular}{|c|c|c|c|c|c|c|}
\hline Tiposangüíneo & $N$ & FF $\%$ & $\operatorname{RhD}(+)$ & FF $\%$ & $\mathrm{RhD}(-)$ & FF \% \\
\hline$\overline{\mathbf{A}}$ & $\overline{836}$ & $\overline{34,44}$ & 764 & 91,39 & 72 & 8,61 \\
\hline B & 356 & 14,67 & 330 & 92,69 & 26 & 7,31 \\
\hline$A B$ & 73 & 3,01 & 65 & 89,04 & 8 & 10,96 \\
\hline 0 & 1162 & 47,88 & 1053 & 90,62 & 109 & 9,38 \\
\hline Totais & $2427 *$ & 100 & 2212 & 91,14 & 215 & 8,86 \\
\hline
\end{tabular}

*56 gemelares, um trigemelar, três recém-nascidos com tipo sangüineo não apurado; FF: freqüência fenotípica

\begin{tabular}{|c|c|c|c|c|}
\hline \multicolumn{5}{|c|}{ Tabela 3 - Ocorrência de concordância RhD entre mãe e recém-nascido } \\
\hline \multicolumn{5}{|c|}{$\begin{array}{llll}\text { Tipo sangǘneo materno } \quad \text { Sim } & \% & \text { Não } & \% \\
\end{array}$} \\
\hline \multicolumn{5}{|c|}{ 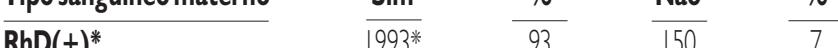 } \\
\hline \multicolumn{5}{|c|}{$\begin{array}{lll}62 & 27 & 167\end{array}$} \\
\hline Totais & 2055 & 86,6 & 317 & 13,4 \\
\hline
\end{tabular}

*Uma mãe com D fraco

\section{Resultados}

A Tabela I mostra a distribuição dos fenótipos dos sistemas ABO e RhD nas puérperas avaliadas. Nas Tabelas 2 e 3, seguem dados relativos aos recém-nascidos vivos de todas as pacientes.

Pudemos apurar nesta casuística de 2372 puérperas avaliadas com seus respectivos recém-nascidos que 436 (18,4\%) apresentaram recém-nascidos ABO incompatíveis. Quando avaliadas exclusivamente as I 67 (7,04\%) RhD negativas que deram à luz pelo menos um concepto $\mathrm{RhD}$ positivo, portanto com risco para aloimunização $\mathrm{RhD}$, a proporção de incompatibilidade $A B O$ manteve-se, sendo 137 (82\%) puérperas de maior risco para sensibilização, por terem recém-nascidos $\mathrm{ABO}$ compatíveis, e 30 ( $18 \%$ ) de baixo risco, por terem conceptos $\mathrm{ABO}$ incompatíveis, conforme Tabela 4.

\section{Discussão}

Os estudos visando a avaliação da distribuição fenotípica dos grupos sangüíneos em nossa população têm sido realizados com a subpopulação de doadores voluntários, junto a serviços de banco de sangue ${ }^{5,6}$. Trazemos neste estudo uma contribuiçã̃o original, avaliando a subpopulação obstétrica de uma grande maternidade, visando basicamente os sistemas $A B O$ e o Rh(D), importantes na DHPN.

As freqüências de grupos sangüíneos obtidas neste estudo, na população da Zona Oeste da cidade de São Paulo, apontaram a ocorrência do antígeno RhD em 90,34\% da casuística, o que está de acordo com outros estudos ${ }^{5-7}$, entre os quais destacamos dois, realizados com doadores voluntários dos maiores hospitais públicos da cidade, Hospital São Paulo ${ }^{5}$ e Hospital das Clínicas ${ }^{6}$, que demonstraram índices de 87,5\% e 91,3\% do antígeno em questão, respectivamente. Este conhecimento pode ser aplicado no planejamento do atendimento das gestantes de risco para aloimunização RhD, que corresponderam em nosso estudo a $7 \%$ de todas as puérperas, sem estratificcção por raça, superponíveis aos percentuais relatados na população norte-americana e britânica, de 9,2\% entre indivíduos brancos e $4,5 \%$ entre negros.

Com relação à incompatibilidade $\mathrm{ABO}$, que poderia reduzir o risco de sensibilização RhD na subpopulação de gestantes RhD negativas, observamos que ocorreu em 18\% destas pacientes, percentual próximo àquele relatado na literatura, de $15 \%{ }^{(8)}$, mostrando que a grande maioria (82\%) das gestantes $\mathrm{RhD}(-)$ geraram descendentes $\mathrm{ABO}$ compatíveis, o que as coloca na condição de maior risco para aloimunização, denotando a importância do emprego da imunoglobulina anti-D na profilaxia da sensibilização materna.

\section{Conclusão}

Concluímos que o contingente de gestantes $\mathrm{RhD}(-)$, em nossa população, foi da ordem de 10\%. Observamos que $73 \%$ destas mulheres geraram descendentes $\mathrm{RhD}(+)$, sendo que $82 \%$ destes nascimentos apresentaram $A B O$ compatibilidade materno-fetal, o que coloca seis em cada dez gestantes RhD negativas na condição de maior risco para sensibilização por este antígeno. Estes achados reforçam a necessidade da rigorosa aplicação das normas expedidas pelo Ministério da Saúde ${ }^{9}$ na profilaxia da aloimunização RhD, com aplicação da imunoglobulina anti-D.

Conflito de interesse: não há. 


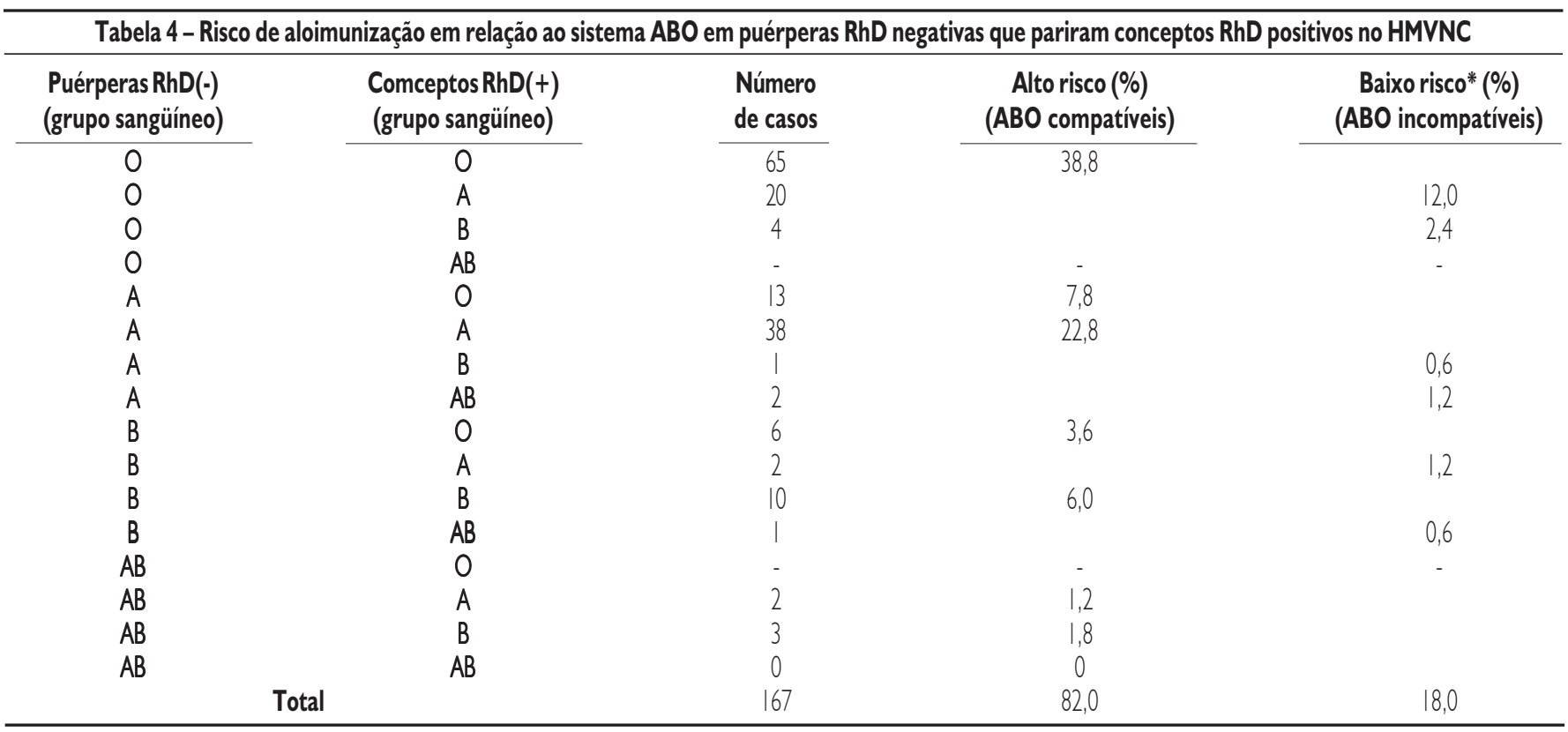

*situação em que anticorpos maternos podem destruir eritrócitos fetais

\section{SUMMARY}

Frequencies of bloOd groups, ABO and $R H$ D INCOMPATIBILITY IN POST-DELIVERY WOMEN AND THEIR LIVEBORN

OBJECTIVE. This study aimed to assess the frequency of different blood phenotypes and to predict the risk of Rh D alloimmunization and maternalfetal incompatibility in a Brazilian population living in the West zone of the city of São Paulo - Brazil.

METHODS. This descriptive study evaluated 2,372 post-delivery women and their liveborn during one year. Blood types were analyzed by means of tube agglutination tests.

RESULTS. The blood type frequencies were: $50.670,32.17 \mathrm{~A}, 13.45 \mathrm{~B}$, 3.75 $A B, 90.34 R h D(+)$ and $9.66 R h D(-)$. $A B O$ maternal-fetal incompatibility was detected in $18.4 \%$ and $R h$ D incompatibility in $7 \%$.

CONCLUSION. The fraction of Rh D(-) population at high risk for $R h D$ alloimmunization was $82 \%$, emphasizing the importance of Rh D alloimmunization profilaxis. [Rev Assoc Med Bras 2007; 53(I): 44-46]

KEY WORDS: Blood groups antigens. ABO blood-group system. Rh-Hr blood group system. Rh isoimmunization.

\section{REFERÊNCIAS}

I. Levine P, Burnham L, Katzin EM, Vogel P. The role of isoimmunization in the pathogenesis of erythroblastosis fetalis. Am J Obstet Gynecol. 1941;42:925-37.
2. Levine P. Serological factors as a possible cause in spontaneous abortions. J Hered. 1943;34:71-80.

3. Bowman JM. Controversies in Rh prophylaxis. Who needs Rh immune globulin and when should it be given? Am J Obstet Gynecol. |985; 151:289-94.

4. American Association Blood Banks. Technical manual. Vengclen-Tyler V, editor. 13 th ed. Maryland: Bethesda; 1999

5. Moreira G, Bordin JO, Kuroda A, Kerbauy J. Red blood cell alloimmunization in sickle cell disease: The influence of racial and antigenic pattern differences between donors and recipients in Brazil. Am J Hematol. 1996;52: 197-200.

6. Novaretti MCZ. Estudo dos grupos sangüíneos em doadores de sangue caucasóides e negróides na cidade de São Paulo [tese]. São Paulo. Faculdade de Medicina, Universidade de São Paulo; 1995.

7. Saluro NN, Otto PA. Blood groups in a large sample from the city of São Paulo (Brazil): allele and haplotype frequencies for MMSs, Kell-Cellano, Rh and ABO systems. Rev Bras Genet. 1989; 12:625-43.

8. Berger GS, Keith L. Utilization of Rh prophylaxis. Clin Obstet Gynecol. 1982;25(2):267-75.

9. Ministério da Saúde. Manual técnico: gestação de alto risco. 3a ed. Brasília: Secretaria de Políticas Públicas, Área Técnica da Saúde da Mulher; 2000. 